\title{
Os custos e a tributação na venda de grãos de milho: estudo de caso de produtor primário no município de Lucas do Rio Verde - MT
}

Neuza Cristina Caeppel Käfer
Mestrado em andamento em Ética e Gestão pela Escola Superior de Teologia - EST
Rua Amadeo Rossi 467. Bairro Morro do Espelho. São Leopoldo/RS
E-mail: neuzakafer@hotmail.com

Dusan Schreiber Doutorado em Administração pela Universidade Federal do Rio Grande do Sul UFRGS Professor da Escola Superior de Teologia - EST Rua Amadeo Rossi 467. Bairro Morro do Espelho. São Leopoldo/RS E-mail: dusan@est.edu.br

Solange Schutz Especialização em Governança Corporativa pela Faculdade La Salle de Lucas do Rio Verde - MT Contadora da Câmara Municipal de Nova Mutum - MT Av. Universitária, 1000 W. Lucas do Rio Verde/MT. CEP: 78455-000 E-mail: solangeschutz@hotmail.com

\section{RESUMO}

O presente estudo teve como objetivo geral analisar as tributações incidentes na venda dos grãos de milho de um produtor primário localizado no município de Lucas do Rio Verde - MT, Safra 2010, considerando-se que a apuração dos custos de produção da cultura e do lucro obtido no período é imprescindível para fornecer dados que auxiliam na tomada de decisão. A realização deste estudo justifica-se pela necessidade de ampliar os estudos sobre a tributação incidente na venda do produto agrícola milho. Metodologicamente, o ambiente pesquisado envolveu um estudo de caso, com a coleta de dados efetuada nas notas fiscais do produtor primário e nas memórias de cálculos dos custos incorridos. Para a interpretação dos dados obtidos serviram de embasamento teórico os estudos sobre custos na produção agrícola e a incidência da tributação na venda dos grãos de milho. O estudo revelou que os insumos e o combustível são responsáveis pela maior parte dos custos diretos de produção.

Palavras-chaves: Custos. Impostos. Produtor Primário. Legislação.

Costs and taxation on sale of grains: study of primary producer in the municipality of Lucas do Rio Verde - MT 


\section{ABSTRACT}

The study aimed to analyze the incident taxes on sale of corn grain in a farmer located in the municipality of Lucas do Rio Verde - MT, 2010 crop, considering that the calculation of crop production costs and the income for the period is essential to provide data do assist in decision making. The study is justified by the need to expand the studies on taxation on the sale of agricultural corn product. Methodologically, this research involved a case study with data collection performed on the invoices of the primary producer and the calculations of costs incurred memories. For data interpretation and conclusion, was used theoretical framework presented in studies on agricultural production costs and the taxation on the sale of corn. The study shows that the costs involving inputs and fuel are responsible for most of the direct production costs.

Keywords: Costs. Taxes. Primary producer. Legislation.

\section{INTRODUÇÃO}

A produção agrícola é o principal elemento do sistema econômico do município de Lucas do Rio Verde. A partir da agricultura é que surgem possíveis investimentos em outros setores, como o setor de serviços e industrial. O município de Lucas do Rio Verde destaca-se como um dos mais importantes pólos do agronegócio de Mato Grosso e do País. É responsável por 1\% de toda produção brasileira de grãos, embora sua área ocupe apenas $0,04 \%$ do território nacional. Com a agricultura em grande expansão se torna mais variável a economia do município, incentivando à instalação de novas empresas, através da isenção de impostos e da disponibilização de lotes subsidiados com toda a infraestrutura necessária, tendo como preocupação o desenvolvimento sustentável e o equilíbrio social do município, de acordo com dados da Prefeitura Municipal de Lucas do Rio Verde (2013).

As médias e grandes áreas de produção do município de Lucas do Rio Verde produzem grãos e fibras como soja, milho, algodão entre outros. O município é também um dos grandes produtores nacionais de milho segunda safra, estando em $2^{\circ}$ lugar no Médio-Norte do estado de Mato Grosso, segundo dados do IMEA (2013). 
Os custos e a tributação na venda de grãos de milho: estudo de caso de produtor primário no município de Lucas do Rio Verde - MT Neuza Cristina Caeppel Käfer, Dusan Schreiber, Solange Schutz

A agregação de valor através da diversificação econômica pode vir a gerar a industrialização do produto no mercado local, gerando empregos e renda, alavancando a economia da cidade, além de contribuir para geração de impostos para os cofres municipais, sendo importante também para o crescimento econômico e para o Produto Interno Bruto (PIB).

Como em toda atividade realizada no Brasil (produção, revendas e serviços) existe a obrigatoriedade de se recolher impostos, taxas e contribuições para os cofres Nacional, Estaduais e Municipais. Na atividade rural não é diferente, porém existem alguns benefícios concedidos ao produtor primário, desde que este opte pelo diferimento conforme artigo 333 do Regulamento de Imposto sobre Circulação de Mercadoria e Serviço (RICMS). Existem algumas situações nas vendas dos grãos de milho em que o produtor deverá recolher o Fundo de Apoio a Agricultura - FAC, Fundo de Transporte e Habitação - FETHAB e Fundo de Assistência ao Trabalhador Rural FUNRURAL.

A área cultivada em Mato Grosso é de aproximadamente 1.774.350ha de milho plantado, sendo que Lucas do Rio Verde é considerado o $2^{\circ}$ maior produtor de milho de segunda safra (safrinha) com 150.000ha da região médio-norte do estado do Mato Grosso, segundo dados do IMEA, gerando empregos e crescimento elevado de investimento industrial à economia do município.

Com o crescimento de Lucas do Rio Verde há o interesse em aprimorar os conhecimentos sobre a tributação desse grão envolvendo a venda de milho da safra de 2010. Assim, o estudo foi desenvolvido junto a um produtor primário, que por motivos pessoais preferiu que sua identidade permanecesse no anonimato, cuja propriedade está localizada no Médio-Norte do Estado de Mato Grosso na cidade de Lucas do Rio Verde-MT, com área total de 490ha de área explorada, visando responder a seguinte questão: quais são as tributações incidentes na venda dos grãos de milho efetuada por produtor primário do município de Lucas do Rio Verde - MT, safra 2010? O objetivo geral é analisar as tributações incidentes na venda de grãos de milho realizada pelo produtor primário localizado no município de Lucas do Rio Verde, Safra 2010. 
Os custos e a tributação na venda de grãos de milho: estudo de caso de produtor primário no município de Lucas do Rio Verde - MT Neuza Cristina Caeppel Käfer, Dusan Schreiber, Solange Schutz

O estudo se justifica na medida em que a economia do município de Lucas do Rio Verde gira em torno da atividade agrícola, sendo um dos setores responsáveis pelo crescimento de empregos e de benefícios a sociedade com suas comercializações. Além disso, a legislação do Estado de Mato Grosso vem sendo modificada constantemente, e é uma área que se encontra em constante observação por parte do fisco, permitindo diversas formas de escriturar e apurar os tributos da área rural.

\section{REVISÃO DA LITERATURA}

\subsection{Contabilidade Tributária e Tributos}

Segundo Fabretti (2003, p. 29), "a contabilidade tributária é o ramo da contabilidade que tem por objetivo aplicar na prática conceitos, princípios e normas básicas da contabilidade e da legislação tributária, de forma simultânea e adequada".

Pode se entender ainda que a contabilidade tributária seja a especialização da contabilidade que tem por objetivo o estudo da teoria e a aplicação prática dos princípios e normas básicas da legislação tributária, e é responsável pela apuração dos tributos incidentes na atividade de uma determinada empresa (OLIVEIRA et al., 2005).

O conceito de tributo encontra-se expresso no Art. 3ํำ do Código Tributário Nacional (CTN): "é toda prestação pecuniária compulsória, em moeda ou cujo valor nela se possa exprimir, que não constitua sanção de ato ilícito, instituída em lei e cobrada mediante atividade administrativa plenamente vinculada".

\subsection{Tributos incidentes sobre a atividade rural}

O Imposto sobre Circulação de Mercadorias e Serviços (ICMS) incide sobre a circulação de mercadorias e serviços prestados em relação a serviços de transporte interestadual, intermunicipal e de mercadoria, cobrado conforme enquadramento de cada empresa. Para tal imposto existe o chamado diferimento aplicado na venda da produção agrícola, art. 333 e ss. do Regulamento de ICMS - RICMS c/c art. $7^{\circ}$, do Anexo X do RICMS. 
Os custos e a tributação na venda de grãos de milho: estudo de caso de produtor primário no município de Lucas do Rio Verde - MT

Neuza Cristina Caeppel Käfer, Dusan Schreiber, Solange Schutz

Art. $7^{\circ}$ O lançamento do imposto incidente na saída de estabelecimento produtor de produto in natura, de origem mato-grossense, não arrolado no Capítulo II do Título V do Livro I das disposições permanentes e neste Anexo, ao qual não se atribua outro tratamento tributário específico, neste regulamento ou na legislação tributária, poderá ser diferido para o momento em que ocorrer:

I - sua saída para outra unidade federada ou para o exterior;

II - sua saída para outro estabelecimento comercial ou industrial, ainda que pertencente ao mesmo titular;

III - a saída resultante do seu beneficiamento ou industrialização.

Parágrafo único $\mathrm{A}$ fruição do deferimento em hipótese abrigada neste artigo, ainda que a saída seja promovida por estabelecimento produtor equiparado a comercial ou industrial, é opcional e sua utilização implica ao mesmo:

I - renúncia ao aproveitamento de quaisquer créditos;

II - aceitação como base de cálculo dos valores fixados em lista de preços mínimos, divulgadas pela Secretaria de Estado de Fazenda, quando houver.

No caso do produtor rural, é a transferência da responsabilidade pelo pagamento do imposto referente às operações anteriores, ao industrial ou comercial. No deferimento, o substituto é o responsável pelo pagamento do imposto devido, não somente sobre suas operações, mas também sobre as anteriores.

Todo produtor rural para usufruir do benefício do diferimento do ICMS terá que recolher o FETHAB, FAC nas operações de venda internas no estado de Mato Grosso. No Capítulo III, sessão I, artigo 10 do Decreto no 1.950/09 consta:

Art. 10 - O benefício do deferimento do Imposto sobre Operações relativas à Circulação de Mercadorias e sobre Prestações de Serviços de Transporte Interestadual e Intermunicipal e de Comunicação - ICMS, previsto na legislação estadual para as operações internas com soja, gado em pé e madeira, fica condicionado a que os contribuintes, remetentes da mercadoria, contribuam para o FETHAB e, ainda, quando for o caso, para o Fundo de Apoio à Cultura da Soja - FACS, ao Fundo de Apoio à Bovinocultura de Corte - FABOV, ao Fundo de Apoio à Madeira - FAMAD, bem como para o Instituto Matogrossense de Algodão - IMAMT. 
Os custos e a tributação na venda de grãos de milho: estudo de caso de produtor primário no município de Lucas do Rio Verde - MT Neuza Cristina Caeppel Käfer, Dusan Schreiber, Solange Schutz

Deve ainda estar com cadastro regular perante o estado, fazer operações regulares e utilizar documentos idôneos. Conforme art. 339-A do RICMS, "A existência de irregularidade em nome do remetente interrompe o diferimento, obrigando o mesmo a efetuar o recolhimento do imposto correspondente à operação antes da saída da mercadoria".

O valor do FAC por tonelada de soja a ser recolhido na venda interna é de 2,52\% sobre a Unidade Padrão Fiscal - UPF/MT conforme Capítulo II, artigo $7^{\circ}$ parágrafo 1ํㅡㄹ item a da Lei 7.263/2000. O Fundo de Transporte e Habitação - FETHAB foi criado pela lei 7.263 em 27/03/2000 para financiar obras rodoviárias e habitacionais no estado de Mato Grosso, e o seu recolhimento se dá nas operações internas de soja e gado em pé. No decorrer dos anos foi sofrendo alterações e o seu recolhimento se dá nas vendas internas de soja, algodão, gado em pé, madeira e combustíveis.

O valor do FETHAB por tonelada de soja a ser recolhido na venda de soja interna corresponde a 19,21\% sobre a UPF/MT conforme Capítulo II, artigo $7^{\circ}$ parágrafo $1^{\circ}$ item a da Lei 7.263/2000. O valor do FETHAB por cabeça de gado a ser recolhido na

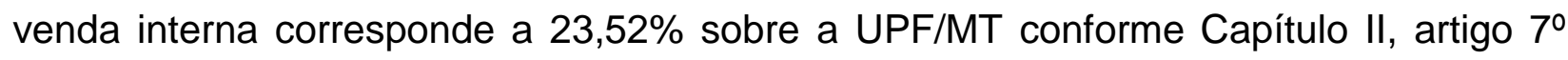
parágrafo $1^{\circ}$ item B da Lei 7.263/2000.

O valor do FETHAB por metro cúbico de madeira a ser recolhido na venda interna corresponde a $18,61 \%$ sobre a UPF/MT, conforme Capítulo II, artigo $7^{\circ}$ parágrafo $1^{\circ}$ item $C$ da Lei $7.263 / 2000$. O valor do FETHAB por tonelada de algodão a ser recolhido na venda interna corresponde a $20,47 \%$ sobre a UPF/MT, conforme Capítulo II, artigo $7^{0}$ parágrafo $1^{0}$ item D da Lei 7.263/2000.

O Fundo de Assistência ao Trabalhador Rural (FUNRURAL) ou contribuição social rural é a contribuição destinada a seguridade geral (INSS), e é cobrado sobre a receita bruta da comercialização de toda a produção rural e descontado pelo adquirente da produção no momento da venda. Conforme o Art. 200 do Decreto № 3.048, de 06 de maio de 1999 
Os custos e a tributação na venda de grãos de milho: estudo de caso de produtor primário no município de Lucas do Rio Verde - MT Neuza Cristina Caeppel Käfer, Dusan Schreiber, Solange Schutz

A contribuição do empregador rural pessoa física, em substituição à contribuição de que tratam o inciso I do art. 201 e o art.202, e a do segurado especial, incidente sobre a receita bruta da comercialização da produção rural, é de:

I - dois por cento para a seguridade social; e

II - zero vírgula um por cento para o financiamento dos benefícios concedidos em razão do grau de incidência de incapacidade laborativa decorrente dos riscos ambientais do trabalho.

O recolhimento ao Serviço Nacional de Aprendizagem Rural (SENAR), criado pela Lei de no 8315 de 1991 e destinado à formação profissional rural em toda região nacional sob forma de cooperação, foi sendo aprimorado pelo Art. 3ํㅜ da Lei № 8.315/91, Art. $2^{\circ}$ da Lei 8.540/92 e Lei 9.528/97, com a redação dada pela Lei 10.256/2001, sendo que o seu recolhimento é de $0,2 \%$ sobre a receita bruta dos produtos vendidos pelo produtor rural (Art. 60 da lei 10.256/2001).

Conforme os parágrafos $1^{\circ}$ e $2^{\circ}$ do Art. 585, capítulo VI do RICMS, a Unidade Padrão Fiscal (UPF) é a importância fixada para o cálculo de multa e limite para efeito de tributação, sendo atualizado pela variação do índice geral de preços disponibilidade interna (IGP-DI), semestralmente.

O Imposto sobre a Renda e Proventos de Qualquer Natureza, de competência da União, é cobrado de qualquer pessoa física ou jurídica com base no resultado da empresa, dos valores recebidos na alienação de bens, negociação financeira, retido em fonte do assalariado, arbitrado ou presumido (Art. 44).

\subsection{Custos na atividade rural}

O controle dos custos da propriedade rural é essencial para o conhecimento dos desembolsos incorridos na produção, possibilitando a percepção de lucro ou prejuízo, visto que a finalidade da contabilidade é fornecer informações para auxiliar na tomada de decisão. O controle de estoques para o produtor rural é indispensável, pois pode se tornar dispendioso, uma vez que ao optar por armazenar adubo de um ano para outro, 
Os custos e a tributação na venda de grãos de milho: estudo de caso de produtor primário no município de Lucas do Rio Verde - MT Neuza Cristina Caeppel Käfer, Dusan Schreiber, Solange Schutz

poderá haver perda deste produto, bem como a armazenagem de sementes pode acarretar na diminuição da germinação.

Como nas indústrias, a atividade agrícola também realiza a produção no próprio estabelecimento, sendo assim, depende muito de um controle eficiente de estoque, já que o custo de produção é a soma de tudo o que se gastou na safra que está se formando, desde gastos antes do plantio até os gastos de comercialização da safra colhida.

$\mathrm{Na}$ contabilidade agrícola podem ser considerados custos diretos os custos com insumos, mão-de-obra direta, depreciação do maquinário e equipamentos usados na produção, e os custos indiretos são atribuídos à produção por algum critério de rateio, como a energia elétrica, impostos e taxas cobrados sobre a propriedade, arrendamentos e a manutenção e peças compradas para manter as máquinas e equipamentos.

Quando se fala em custos e despesas, é comum acreditar que a definição é a mesma, uma vez que ambos acarretam desembolso de numerário do caixa ou no aumento de obrigações. A diferença básica está em que custos dos produtos são todos os recursos que foram usados na cultura que são possíveis de identificação.

Por convenção, e para facilitar a comunicação deste assunto, consideram-se custos de cultura todos os custos identificáveis direta ou indiretamente com a cultura (ou produto), como sementes, adubos, mão-de-obra (direta ou indiretamente), combustíveis depreciação de máquinas e equipamentos utilizados na cultura, serviços agronômicos e topográficos, etc." (MARION 2005, p. 38).

Já as despesas são os recursos utilizados e que não são diretamente identificáveis com a cultura produzida na propriedade. 
Os custos e a tributação na venda de grãos de milho: estudo de caso de produtor primário no município de Lucas do Rio Verde - MT

Neuza Cristina Caeppel Käfer, Dusan Schreiber, Solange Schutz

Como despesas do período, entendem-se todos os gastos não identificáveis com a cultura, não sendo, portanto, acumulados no estoque (culturas temporárias), mas apropriados como despesas do período. São despesas de venda (propaganda, comissão de vendedores...), despesas administrativas (honorários dos diretores, pessoal do escritório...) e despesas financeiras (juros, correção monetária....)" (MARION, 2005, p. 38).

Os custos diretos estão diretamente ligados a produção, não necessitam de um critério de rateio para que eles possam ser atribuídos a cultura para Crepaldi (1998 p. 91) "Custos diretos são aqueles que podem ser diretamente (sem rateio) apropriados aos produtos agrícolas, bastando existir uma medida de consumo". Por este método podemos aferir os desembolsos praticados pelo produtor na cultura em questão.

Alguns dos custos diretos mais frequentes são os insumos utilizados na produção, pois eles foram aplicados diretamente no produto, são sementes, defensivos agrícolas, fertilizantes, o óleo diesel também pode ser considerado um custo direto, e os custos com a mão-de-obra e encargos sociais, férias, décimo terceiro e FGTS (Fundo de Garantido por Tempo de Serviço), são custos diretos, pois podem ser diretamente identificados com a produção.

Os custos indiretos não são diretamente identificáveis à cultura, e para atribuí-los a mesma, faz-se necessário adotar um critério de rateio para distribuí-los, evitando que ocorram distorções nos resultados. Na atividade agrícola têm-se como exemplos os gastos com arrendamento, gastos com contabilidade e depreciação dos maquinários utilizados no preparo do solo e na colheita (CREPALDI, 1998). Ainda, segundo o autor, os custos variáveis são aqueles que variam de acordo com a produção.

Os custos fixos são aqueles que o agricultor terá independente de sua produção, para Crepaldi (1998, p. 92), "custos fixos são aqueles cujo total não varia proporcionalmente ao volume produzido" (aluguel). Mesmo sendo chamados de custos fixos, os valores podem sofrer alterações para mais ou para menos, pois sendo fixos, terão valor mesmo que não exista produção. Eles podem variar dependendo da produção também. Exemplo: se o agricultor tem sempre os mesmos custos fixos e seu 
Os custos e a tributação na venda de grãos de milho: estudo de caso de produtor primário no município de Lucas do Rio Verde - MT Neuza Cristina Caeppel Käfer, Dusan Schreiber, Solange Schutz

rendimento médio está entre 60 e 80 sacas por hectare e no outro ano resolve que vai tentar atingir a meta de 95 a 100 sacas por hectare, isso implicará em um aumento não apenas dos custos variáveis, mas também dos custos fixos.

A relação entre custo e benefício deve sempre estar presente na mente do produtor rural, pois ele deve analisar todas as possibilidades e cultivar a variedade mais rentável para a propriedade.

"O controle das atividades agrícolas em empreendimentos rurais, fundamentais para a correta avaliação dos mesmos e posterior tomada de decisão (vale a pena plantar? Qual é a melhor alternativa: milho ou soja?) deve integra-se ao cotidiano do produtor" (CREPALDI, 1998, p. 144).

Antes do plantio de cada cultura o agricultor deve fazer o cálculo para saber se o que ele está planejando plantar dará realmente o resultado esperado. Devido ao fator climático da região de Lucas do Rio Verde, o produtor deverá iniciar o cultivo do milho imediatamente ao término da colheita da soja, para evitar que a estiagem prejudique a formação final da lavoura de milho.

Uma opção para a produção de milho quando for em época tardia é plantá-lo com baixos investimentos, pois este cultivo traz vários benefícios como o controle de ervas daninhas, uma vez que a terra fica produtiva, impedindo que as ervas daninhas cresçam e formem sementes que podem vir a atrapalhar a soja depois. O milho produz matéria orgânica rica em potássio e a sua palhada ajuda a manter a umidade do solo (não deixa o solo exposto ao sol e ao vento, diminuindo a evaporação).

Antes do início da colheita os custos com a produção da cultura são lançados em uma conta que é da cultura em formação, mas quando chega a hora de colher esse produto, ele já não está mais em formação, ou seja, é um produto acabado, então criase uma conta para produtos acabados e transfere-se os saldos da cultura em formação somando os custos da colheita, resultando, assim, no valor do produto agrícola em estoque. Quando o mesmo é vendido dá-se baixa no estoque de forma proporcional a quantidade vendida, apurando-se o custo dos produtos vendidos. 
Os custos e a tributação na venda de grãos de milho: estudo de caso de produtor primário no município de Lucas do Rio Verde - MT Neuza Cristina Caeppel Käfer, Dusan Schreiber, Solange Schutz

A essa conta de "Produtos Agrícolas" serão somados todos os custos posteriores à colheita (para acabamento do produto ou deixá-lo em condições de ser vendido, consumido ou reaplicado, tais como beneficiamentos, acondicionamento etc.) e todos os custos para a manutenção desse estoque: silagem, congelamento etc. (MARION, 2005, p. 39).

Alguns produtores não vendem imediatamente seus produtos após a colheita e permanecem com eles armazenados a espera de um preço melhor. Os gastos com esse armazenamento são lançados como despesas do período, mas estes gatos também podem ser lançados como custos, ficando assim mais evidente o custo final do produto vendido.

Todavia, considerando que o produto agrícola pode ficar em estoque para vendas futuras (especulação), algumas vezes ultrapassando um ano, há quem prefira contabilizar os gastos de armazenamento acumulado no custo (estoque), identificando melhor o custo do produto no momento da venda. (MARION, 2005, p. 39).

\subsection{Cultura do milho}

O milho é um dos cereais mais consumidos hoje no mundo, juntamente com o trigo e o arroz. A sua origem é americana, onde era cultivado pelas civilizações précolombianas e após o "descobrimento" da América ele foi espalhado primeiramente pela Europa depois pelo mundo todo (GRANDE ENCILOPÉDIA BARSA, v. 10, 2004).

O seu ciclo varia de acordo com sua variedade, existindo espécies de milhos mais precoces que possuem o seu ciclo de 120 dias e outras mais tardias que podem chegara 160 dias.

Ele é de grande importância alimentar, pois mesmo verde já é possível consumilo. Quando os grãos estão em processo de enchimento não completamente desenvolvido, as espigas são colhidas e cozidas para a alimentação ou até mesmo os grãos são retirados da espiga para fazer o curau, a pamonha e até mesmo alguns bolos. Antes de secar, o milho também pode ser usado na alimentação de animais por 
Os custos e a tributação na venda de grãos de milho: estudo de caso de produtor primário no município de Lucas do Rio Verde - MT Neuza Cristina Caeppel Käfer, Dusan Schreiber, Solange Schutz

meio da silagem, onde o pé de milho é cortado inteiro e moído. E quando seca, o milho é colhido e seus grãos possuem diferentes utilidades que servem desde a alimentação animal até a alimentação humana.

\section{METODOLOGIA}

O método de pesquisa escolhido foi o estudo de caso, por se entender que apresenta melhor aderência ao objetivo e à questão que nortearam o estudo. Tull e Hawkins (1976, p. 323) afirmam que "um estudo de caso refere-se a uma análise intensiva de uma situação particular". De acordo com Yin (2010), a preferência pelo uso do estudo de caso deve ser no estudo de eventos contemporâneos, em situações onde os comportamentos relevantes não podem ser manipulados, mas onde é possível se fazer observações diretas e entrevistas sistemáticas. O estudo de caso permite análise aprofundada de um fenômeno através dos aspectos que o constituem, permitindo ao pesquisador compreender as complexidades inerentes ao evento (GIL, 2009; YIN, 2010). Dessa forma, o estudo foi realizado com uma visão externa dos pesquisadores, sem envolvimento nem manipulação de quaisquer informações e os fatos levantados pelo estudo são contemporâneos.

Foram coletados dados das notas fiscais de venda emitidas pelo produtor primário no ano de 2010 e efetuadas consultas às memórias de cálculo das planilhas de custos da propriedade.

O estudo também pode ser considerado descritivo por analisar as características do fenômeno em tela, relacionando as variáveis sem interferência do pesquisador, e exploratório, devido ao conhecimento restrito que se tem a respeito da questão em estudo (CERVO; BERVIAN, 2002; GIL, 2009; ANDRADE, 2009). 
Os custos e a tributação na venda de grãos de milho: estudo de caso de produtor primário no município de Lucas do Rio Verde - MT Neuza Cristina Caeppel Käfer, Dusan Schreiber, Solange Schutz

\section{APRESENTAÇÃO E ANÁLISE DOS DADOS}

\subsection{Custos que fizeram parte da composição da safra de milho 2010 do produtor primário}

O produtor primário pesquisado possui uma área cultivada de 490 hectares, na qual obteve uma colheita de 34.421 sacas de milho. A produção da safra 2010 apresentou os seguintes custos com base nas memórias de cálculo cedidas pela propriedade:

Tabela 1 - Custos Totais

\begin{tabular}{|c|c|}
\hline Sementes & $\mathrm{R} \$ 60.031,94$ \\
\hline Uréia 46\% & $\mathrm{R} \$ 43.630,75$ \\
\hline Adubo NPK18-00-36 & $\mathrm{R} \$ 61.106,75$ \\
\hline Saluzi 600 FS & $\mathrm{R} \$ 7.588,87$ \\
\hline Saddler & $\mathrm{R} \$ 8.103,37$ \\
\hline Roundup WG & $\mathrm{R} \$ 6.097,89$ \\
\hline Cefanol & $\mathrm{R} \$ 5.492,65$ \\
\hline Herbitrin 500 BR & $\mathrm{R} \$ 8.268,75$ \\
\hline Assist & $\mathrm{R} \$ 1.051,78$ \\
\hline Nomolt 150 & $\mathrm{R} \$ 8.223,42$ \\
\hline Imunit & $\mathrm{R} \$ 6.801,12$ \\
\hline Óleo Diesel & $\mathrm{R} \$ 14.594,06$ \\
\hline Funcionários & $\mathrm{R} \$ 9.627,19$ \\
\hline Peças & $\mathrm{R} \$ 12.135,33$ \\
\hline Frete & $\mathrm{R} \$ 17.210,50$ \\
\hline Total & $\mathrm{R} \$ 269.964,43$ \\
\hline
\end{tabular}

Fonte: Dados da pesquisa (2013).

O custo médio por saca de milho produzido é de $\mathrm{R} \$ 7,84$ (sete reais e oitenta e quatro centavos) e pode-se perceber que o custo mais relevante é quanto aos insumos, que juntos chegam a ultrapassar mais da metade dos custos totais da produção da propriedade pesquisada. A receita média obtida por saca de milho comercializada foi de $\mathrm{R} \$ 14,05$ (quatorze reais e cinco centavos), o que num confronto inicial com o custo resultou num lucro bruto de $R \$ 6,21$ (seis reais e vinte e um centavos), e após a incidência dos tributos na emissão da nota fiscal de venda o lucro líquido resultou em 
Os custos e a tributação na venda de grãos de milho: estudo de caso de produtor primário no município de Lucas do Rio Verde - MT Neuza Cristina Caeppel Käfer, Dusan Schreiber, Solange Schutz

$\mathrm{R} \$ 5,89$ (cinco reais e oitenta e nove centavos) por saca para o produtor, ressaltando que não foram consideradas as despesas do período na apuração final do resultado (Tabela 2).

Tabela 2 - Apuração do resultado líquido da colheita do milho safra 2010

\begin{tabular}{|c|c|c|}
\hline Receita Total do Ano de 2010 & & $483.698,01$ \\
\hline Custos Totais do Ano de 2010 & & $(269.964,43)$ \\
\hline Lucro Bruto do Ano de 2010 & & $213.733,58$ \\
\hline Impostos sobre a venda da Safra 2010 & & \\
\hline Funrural & & $(10.157,65)$ \\
\hline FEHTAB & & $(913,14)$ \\
\hline Lucro líquido da safra de milho 2010 & $202.662,79$ \\
\hline Total de Sacas colhidas na safra 2010 & 34.421 & \\
\hline Lucro líquido por saca & & 5,89 \\
\hline
\end{tabular}

Fonte: Dados da pesquisa (2013).

\subsection{Aplicação da legislação tributária pelo produtor primário nas operações mercantis de milho, safra 2010.}

$\mathrm{Na}$ venda de milho a cobrança do FUNRURAL de 2,1\% distribuído da seguinte forma: $2,0 \%$ a Previdência Social, $0,1 \%$ para risco ambiental do trabalho - RAT conforme "art. 200 do Decreto de n 3048 de 06 de maio de 1999" e de 0,2\% para Serviço Nacional de Aprendizagem Rural - SENAR criado pela Lei 8315 de 1991e atualizada pela Lei de № 8540/92, no 9528/97 e 10.256/91, ambos calculados pelo valor bruto da venda de produtos in natura e recolhido pela mesma guia.

O recolhimento do Funrural é de responsabilidade do adquirente da mercadoria conforme inciso $V$ do artigo 184 da instrução normativa RFB 971/09. O prazo para recolhimento do funrural conforme inciso III do artigo 80 da instrução normativo RFB 971/09 é no vigésimo dia seguinte da aquisição do produto. 
Os custos e a tributação na venda de grãos de milho: estudo de caso de produtor primário no município de Lucas do Rio Verde - MT Neuza Cristina Caeppel Käfer, Dusan Schreiber, Solange Schutz

Tabela 3 - Descrição das notas fiscais de venda de milho do período de Janeiro a dezembro de 2010

\begin{tabular}{|c|c|c|c|c|c|c|}
\hline $\mathbf{N}^{\circ}$ da NF & PJ / PF & CFOP & Data & Descr. & Quant. & Valor NF \\
\hline 306 & PJ & 5.101 & 01/Fev & Milho & Complementar & $2.280,00$ \\
\hline $403 / 405$ & PJ & 5.101 & $10 /$ Nov & Milho & 199.920 & $46.793,79$ \\
\hline $406 / 410$ & PJ & 5.101 & $10 /$ Nov & Milho & 345.168 & $80.424,14$ \\
\hline $411 / 420$ & PJ & 5.101 & $10 /$ Nov & Milho & 833.640 & $194.238,12$ \\
\hline $421 / 432$ & PJ & 5.101 & $11 /$ Nov & Milho & 686.532 & $159.961,96$ \\
\hline \multicolumn{5}{|c|}{ Total do Ano de 2010} & 2.065 .260 & $483.698,01$ \\
\hline
\end{tabular}

Fonte: Dados da pesquisa (2013).

Na venda de milho em grãos o produtor rural tem o benefício do diferimento da cobrança de ICMS conforme art. 333, inciso I, item b do capítulo II do RICMS;

Art. 333 O lançamento do imposto incidente nas saídas de: I - arroz em casca, feijão e soja em vagem ou batidos, milho em palha, em espiga ou em grão e semente de girassol de produção mato-grossense, poderá ser diferido para o momento em que ocorrer:

$[\ldots]$

b) sua saída para outro estabelecimento comercial ou industrial;

Tabela 4 - Cálculo do FUNRURAL e SENAR sobre a venda de milho do período de Janeiro a dezembro de 2010

\begin{tabular}{|c|c|c|c|c|c|c|c|c|}
\hline \multirow{2}{*}{$\begin{array}{c}\mathrm{N}^{\circ} \mathrm{da} \\
\mathrm{NF}\end{array}$} & \multirow{2}{*}{$\begin{array}{l}\text { PJ / } \\
\text { PF }\end{array}$} & \multirow{2}{*}{ CFOP } & \multirow{2}{*}{ Data } & \multirow{2}{*}{ Descr. } & \multirow{2}{*}{ Quant. } & \multirow{2}{*}{ Valor NF } & \multirow{2}{*}{\begin{tabular}{|c|} 
FUNURAL \\
$2,1 \%$
\end{tabular}} & \multirow{2}{*}{$\begin{array}{c}\text { SENAR } \\
0,2 \%\end{array}$} \\
\hline & & & & & & & & \\
\hline 306 & PJ & 5.101 & 01/01 a 31/01 & lilho & Complementar & $2.280,00$ & 47,88 & 4,56 \\
\hline $\begin{array}{c}403 \text { á } \\
432\end{array}$ & PJ & 5.101 & $01 / 11$ a $30 / 11$ & Milho & 2.065 .260 & $481.418,01$ & $10.109,77$ & 926,84 \\
\hline \multicolumn{5}{|c|}{ Total do Ano de 2010} & 2.065 .260 & $483.698,01$ & $10.157,65$ & 913,14 \\
\hline
\end{tabular}

Fonte: Dados da pesquisa (2013). 
Os custos e a tributação na venda de grãos de milho: estudo de caso de produtor primário no município de Lucas do Rio Verde - MT Neuza Cristina Caeppel Käfer, Dusan Schreiber, Solange Schutz

Observou-se que em algumas notas fiscais do produtor rural havia o destacamento dos impostos e contribuições e em outras o mesmo não foi observado, mas em todas as vendas de milho ocorreu o recolhimento devido dos impostos.

\section{CONSIDERAÇÕES FINAIS}

Esta pesquisa permitiu uma análise da legislação do Estado de Mato Grosso para a comercialização de grãos de milho, trazendo como objetivo geral a apuração dos custos da produção da cultura do milho, ou seja, quais os tributos incidentes na venda de milho realizada pelo produtor primário localizado no município de Lucas do Rio Verde, Safra 2010.

Após identificar os custos de produção de milho na propriedade analisada, pode se perceber que os custos que envolvem os insumos e o combustível são responsáveis pela maior parte dos custos diretos da produção. Apurou-se, também, que o produtor obteve um lucro médio de $R \$ 6,21$, e após a dedução dos tributos incidentes na emissão da Nota Fiscal de venda o lucro líquido por saca resultou em $R \$ 5,89$, o que corresponde em termos percentuais à aproximadamente $41,92 \%$ de lucro líquido, ressaltando que não foram consideradas para esta análise as despesas do período. $O$ produtor considerou o resultado satisfatório, uma vez que historicamente o preço do milho sofre com as influências da produção no exterior.

Na pesquisa realizada também foi possível identificar que a tributação incidente na comercialização dos grãos de milho é constituída pelo FAC, FETHAB, Funrural, juntamente com o SENAR. O ICMS não incide sobre a comercialização dos grãos, em função do diferimento.

Por fim, a pesquisa proporcionou um conhecimento acerca dos custos envolvidos na produção da cultura de milho numa propriedade rural do município de Lucas do Rio Verde, MT, bem como o entendimento a respeito dos tributos incidentes na sua comercialização. 
Os custos e a tributação na venda de grãos de milho: estudo de caso de produtor primário no município de Lucas do Rio Verde - MT Neuza Cristina Caeppel Käfer, Dusan Schreiber, Solange Schutz

\section{REFERÊNCIAS}

ANDRADE, Maria M. (2009). Introdução à metodologia do trabalho científico. (9 ed.). São Paulo: Atlas.

BONOMA, T. V. (1985). Case research in marketing: opportunities, problems, and process. Journal of Marketing Research, v.22, n.2, p.199-208.

BRASIL. (2008). Código Tributário Nacional, Código Comercial, Código civil (excertos), legislação Tributária e Empresarial, Constituição Federal. Organização dos textos por Roque Antonio Carrazza e Vera Helena de Mello franco. (10 ed.). São Paulo: Editora Revista dos Tribunais.

BRASIL. Decreto 3.048, de 06 de maio de 1999. Presidência da República, Casa Civil Brasília, DF. Disponível em: <http://www.planalto.gov.br/ccivil_03/decreto/d3048.htm >. Acesso em: 06/maio/2013.

BRASIL. Mato Grosso, Lucas do Rio Verde. Economia Municipal. Disponível em: <http://www.lucasdorioverde.mt.gov.br/economia.asp>. Acesso em: 24/abril/2013.

CERVO, Amado L.e BERVIAN, Pedro A. (2002). Metodologia Científica. (5 ed.). São Paulo: Pretince Hall.

FABRETTI, L. C. (2005). Contabilidade Tributária. (9 ed.). São Paulo: Atlas S.A.

FAZENDA do Estado de Mato Grosso, Palácio Paiaguás, Cuiabá, MT. Disponível em: $<$ http://www.sad-

legislacao.mt.gov.br/Aplicativos/Sadlegislacao/legislacaosad.nst/5edf9c5193c58088032

$567580038916 \mathrm{~b} / 3 \mathrm{a} 4 \mathrm{f} 0 \mathrm{~d} 55269 \mathrm{ff} 4 \mathrm{~d} 504256 \mathrm{ed} 20043 \mathrm{~b} 15 \mathrm{e}$ ?OpenDocument>. Acesso em: 05/maio/2013.

GIL, A. C. (2009). Métodos e técnicas de pesquisa social. (6 ed.). São Paulo: Atlas.

HARTLEY, Jean F. Case studies in organizational research. In: CASSELL, Catherine \& SYMON, Gillian (Ed.). Qualitative methods in organizational research: a practical guide. London: Sage, 1994. 253p. p. 208-229

MARION, J. C. (2004). Contabilidade Básica. (7 ed.). São Paulo: Atlas S.A.

MARION, J. C. (2012). Contabilidade Rural: contabilidade agrícola, contabilidade da pecuária, imposto de renda - pessoa jurídica. (12 ed.). São Paulo: Atlas S.A. 
Os custos e a tributação na venda de grãos de milho: estudo de caso de produtor primário no município de Lucas do Rio Verde - MT

Neuza Cristina Caeppel Käfer, Dusan Schreiber, Solange Schutz

MATO GROSSO. Decreto 1.950, de 27 de maio de 2009. Secretária da Fazenda do Estado de Mato Grosso, Palácio Paiaguás, Cuiabá, MT. Disponível em: $<$ http://app1.sefaz.mt.gov.br/Sistema/Legislacao/legislacaotribut.nsf/fraWebDocumento? OpenFrameSet\&Frame $=$ frmFrame2\&Src $=\_c 5 t 9$ misrkclmm2bqccljmisrcc5hm2rpfdhimeq bjdhgm6obfehp6iojlegn6ssr65ti3aopg6kp3ac9l70o62or6clij0d1i6krj0d9n60o3edpp65hm 2fqfe1imshjfe9micgblehnkcsj1dlim80_ >. Acesso em: 05/maio/2013.

MATO GROSSO. Regulamento do ICMS. Secretária da Fazenda do Estado de Mato Grosso, Palácio Paiaguás, Cuiabá, MT. Disponível em: <http://app1.sefaz.mt.gov.br/sistema/legislacao/regulamentoicms.nsf >. Acesso em: 05/maio/2013.

OLIVEIRA, L. M. et al. (2011). Manual de Contabilidade Tributária. (10 ed.). São Paulo: Atlas S.A.

PADOVEZE, C. L.; (2004). Manual de Contabilidade Básica: uma introdução à prática contábil. (5 ed.). São Paulo: Atlas.

PUBLICAÇÃO. Mato Grosso: IMEA. Informativo Plantio Milho Safra 2009/2010. Disponível em: <http://www.imea.com.br/upload/publicacoes/arquivos/10_03_18_IPMilho.pdf>. Acesso em: 24/abril/2013.

PUBLICAÇÃO. Mato Grosso: IMEA. Informativo Plantio Safra Soja 2009/2010. isponível em: <http://www.imea.com.br/upload/publicacoes/arquivos/09_12_03_APSoja.pdf>. Acesso em: 24/abril/2013.

REZENDE, A. J; PREIRA, C. A. e ALENCAR, R. C. (2010). Contabilidade Tributária: Entendendo a Lógica dos Tributos e seus Reflexos sobre os Resultados das Empresas. São Paulo: Atlas S.A.

SABBAG, E.; (2010). Manual de Direito Tributário. (2 ed.). São Paulo: Saraiva.

SILVA, L. L.; (2007). Contabilidade Gerencial e Tributária. (4 ed.). São Paulo: IOB Thomson.

TULL, D. S. \& HAWKINS, D. I. (1976). Marketing Research, Meaning, Measurement and Method. Macmillan Publishing Co., Inc., London.

YIN, Robert. K. (2010). Estudo de caso: planejamento e métodos. (4 ed.). Porto Alegre: Bookman. 
Os custos e a tributação na venda de grãos de milho: estudo de caso de produtor primário no município de Lucas do Rio Verde - MT

Neuza Cristina Caeppel Käfer, Dusan Schreiber, Solange Schutz

Data de Submissão: 16/06/2014

Data de Aceite: 19/03/2015 